\title{
Produção de mudas de almeirão e cultivo no campo, em sistema agroecológico
}

\author{
Dercio C. Pereira ${ }^{1}$, Priscila G rutzmacher ${ }^{2}$, Francieli H. Bernardi ${ }^{1}$, \\ Larissa S. Mallmannn ${ }^{1}$, Luiz A. de M. Costa $^{3} \&$ Mônica S. S. de M. Costa ${ }^{4}$
}

RESU M O

O bjetivou-se, neste trabalho, avaliar o desenvolvimento das mudas de almeirão em diferentes substratos orgânicos e verificar o comportamento em bandejas, após o transplante no campo e na pós-colheita, constituindo três experimentos. Foram avaliados o uso do substrato comercial e quatro misturas de proporções de composto, areia e pó de basalto. Foram quatro fases de avaliação: aos 13 e 26 dias após a emergência (DAE), aos 74 dias após o transplante e na pós-colheita. Avaliaram-se o comprimento e a massa da matéria seca de raiz e de parte aérea, número de folhas por planta, diâmetro do coleto, área foliar e a conservação pós-colheita. 0 composto orgânico e as misturas foram superiores ao substrato comercial, na maioria das características avaliadas nos 13 e $26 \mathrm{DAE}$; entretanto, o substrato comercial superou os demais tratamentos para o comprimento de raiz. O s substratos orgânicos $\left(T_{2}\right.$ e $\left.T_{3}\right)$ podem ser recomendados para a produção de mudas de almeirão com desenvolvimento satisfatório em sistema de cultivo em bandejas e a campo e, de igual forma, em pós-colheita; o uso de composto orgânico como substrato para produção de mudas propiciou o desenvolvimento de mudas mais vigorosas e plantas mais resistentes no campo do que o substrato comercial.

Palavras-chave: análise de crescimento, Cichorium intibus L., composto orgânico, pó de rocha

\section{Agroecological seedling production and field cultivation of chicory}

\section{ABSTRACT}

This study aimed to evaluate the development of chicory seedlings in different organic substrates and verify its behavior in trays, after transplanting in field and in post-harvest, constituting three experiments. Commercial substrate and four mixtures with different proportions of compost, basalt pow der and sand were evaluated. Four stages of assessment were: 13 and 26 days after emergence (D AE), at 74 days posttransplant and post-harvest. The length and dry mass of roots and shoots, number of leaves plant ${ }^{1}$, stem diameter, leaf area and post-harvest conservation were evaluated. The organic compost and the mixtures were superior to commercial substrate in most of the characteristics evaluated at 13 and 26 DAE. However, the commercial substrate was superior to other treatments for root length. The organic substrates can be recommended for seedling production of chicory with a satisfactory development in trays and in the field, and also at post-harvest. The use of compost as a substrate for seedlings provided the development of more vigorous seedlings and stronger plants in field than the commercial substrate.

Key words: analysis of growth, basalt powder, Cichorium intibus L., organic compound

${ }^{1}$ D outorando em Engenharia A grícola U niversidade Estadual do O este do Paraná. Rua U niversitária, 2069, CEP 85819-110, Cascavel, PR. E-mail: dercioceri@gmail.com; fran.bernardi@yahoo.com.br; Iarissasmallmann@gmail.com

2 Doutoranda em Agricultura Tropical e Sub-tropical Instituto Agronômico - IAC. Av. Barão de Itapura, 1481, CEP 13020-902, Campinas, SP. Fone: (19) 2137-0670. E-mail: priscila.grutzmacher@gmail.com

${ }^{3}$ Bolsista CN Pq/RHAE. Rua Di Cavalcanti, 283, CEP 85813-280, Cascavel, PR. Fone: (45) 3223-0122. E-mail: Imendo@ig.com.br

${ }^{4}$ UNIOESTE. E-mail: monica.costa@unioeste.br 


\section{INTRODUÇÃO}

Sustentabilidade ambiental, social e econômica, é o que preconiza a agroecologia, cujo interesse é praticar a agricultura limpa e racional, empregando-se a biodiversidade de modo equilibrado, satisfazendo as necessidades das culturas e do agricultor. O uso de substratos constituídos pela mistura do composto e de alguns subprodutos, tais como casca de arroz, serragem, bagaço da cana-de-açúcar, pó de rocha, fibra de coco e areia (Fernandes et al., 2006) favorece a sustentabilidade da pequena e média propriedade. Possuem capacidade de suprir completamente a demanda por nutrientes eliminando a utilização de fertilizantes químicos e podem ser obtidos com facilidade na propriedade rural ou imediações, fatos que propiciam menores custos ao produtor rural (Leal et al., 2007; Factor et al., 2008). Esses materiais são misturados a fim de proporcionar condições químicas, físicas e biológicas adequadas ao bom desenvolvimento das plantas.

O substrato está entre os principais fatores que propiciam a produção de mudas de qualidade. Segundo Wagner Júnior et al. (2007) é responsável pelo crescimento rápido e adequado das raízes, apresentando reflexo no vigor das plantas. Além disto, os substratos devem ser facilmente obtidos na região e com baixo custo (Blank et al., 2003).

A produção de mudas é a fase fundamental do sistema produtivo, afetando diretamente o desenvolvimento das plantas no campo, sobretudo para alcançar sucesso na exploração (Reghin et al., 2006; Echer et al., 2007). Com isto, a opção por substratos é uma tomada de decisão essencial para produtores de mudas, especialmente quando as condições de cultivo estão sujeitas às exigências das espécies a serem cultivadas (Silveira et al., 2002). Conforme as necessidades das espécies são necessárias observações científicas quanto aos substratos ou combinação de substratos, para obtenção de mudas de qualidade (Oliveira et al., 2008).

Algumas culturas são semeadas indiretamente, ou seja, em bandeja, para posterior transplante. $\mathrm{O}$ tomate, o pepino, a beterraba, a alface, a couve-chinesa, a cebola, o repolho, a berinjela e o brócolis, são exemplos de mudas produzidas em bandejas. $\mathrm{O}$ almeirão pertence à família Asteraceae, a mesma da alface; trata-se de uma planta rústica, que possibilita semeadura em bandeja e se desenvolve bem em temperaturas de 12 a $24{ }^{\circ} \mathrm{C}$ porém é pouco tolerante ao transplante; seu sistema radicular é pivotante, sem ramificações laterais e em canteiro responde bem à adubação orgânica podendo ser realizado com esterco de bovino "in natura" ou compostado, uma ou duas semanas antes da semeadura. A colheita se inicia aos 50 dias após a semeadura, no verão, e 70 dias no inverno (Sediyama et al., 2007). Foi objetivo deste trabalho avaliar o desenvolvimento das mudas de almeirão sob diferentes substratos orgânicos e verificar o comportamento em bandejas, após o transplante no campo e na pós-colheita.

\section{Material e MÉTOdos}

Foram conduzidos três experimentos, um sob estufa, outro a campo e em laboratório, para avaliação da pós-colheita do almeirão. $\mathrm{O}$ primeiro experimento foi conduzido em estufa modelo arco, localizada na área experimental da Universidade Estadual do Oeste do Paraná (UNIOESTE), em Cascavel, PR, na latitude de $24^{\circ} 59^{\prime} 20,70$ "S e longitude de $53^{\circ} 26^{\prime} 59,99^{\prime \prime} \mathrm{W}$, com altitude média de 756 metros. O clima, segundo a classificação de Köppen, se enquadra no tipo Cfa, com temperatura média anual de $19,5^{\circ} \mathrm{C}$ e precipitação média anual de $1.950 \mathrm{~mm}$ (IAPAR, 1994). Para o primeiro experimento foi utilizado delineamento experimental inteiramente casualizado, com dezesseis repetições de plantas por bandeja. Foram utilizadas cinco bandejas de poliestireno expandido de 200 células, uma para cada substrato.

Os tratamentos foram: $\mathrm{T}_{0}$ - Plantmax ${ }^{\circledR} ; \mathrm{T}_{1}-100 \%$ composto; $\mathrm{T}_{2}-95 \%$ composto $+2,5 \%$ areia $+2,5 \%$ pó de basalto; $\mathrm{T}_{3}-90 \%$ composto $+3 \%$ areia $+7 \%$ pó de basalto; $\mathrm{T}_{4}-85 \%$ composto + $6 \%$ areia $+9 \%$ pó de basalto. O composto foi obtido a partir da compostagem de resíduos de bovinos em regime de semiconfinamento e resíduos da máquina de prelimpeza (resíduos de milho). A compostagem foi manejada durante três meses, mediante revolvimentos e irrigações. A composição química do composto e dos substratos é apresentada na Tabela 1.

Tabela 1. Análise química dos substratos utilizados

\begin{tabular}{|c|c|c|c|c|c|}
\hline Substratos & $\mathrm{T}_{0}$ & $\mathrm{~T}_{1}$ & $\mathrm{~T}_{2}$ & $\overline{T_{3}}$ & $\mathrm{~T}_{4}$ \\
\hline $\mathrm{pH}$ & 5,1 & 6,0 & 6,0 & 6,0 & 5,9 \\
\hline C (\%) & 14,2 & 15,2 & 14,8 & 14,0 & 14,0 \\
\hline $\mathrm{H}+\mathrm{Al}\left(\mathrm{cmol}_{\mathrm{c}} \mathrm{dm}^{-3}\right)$ & 5,9 & 3,8 & 3,8 & 3,8 & 3,8 \\
\hline$P\left(\mathrm{mg} \mathrm{dm}^{-3}\right)$ & 298,3 & 461,6 & 440,9 & 468,5 & 436,1 \\
\hline $\mathrm{K}\left(\mathrm{cmol}_{\mathrm{c}} \mathrm{kg}^{-1}\right)$ & 0,2 & 1,1 & 1,1 & 1,1 & 1,1 \\
\hline $\mathrm{Ca}\left(\mathrm{cmol}_{\mathrm{c}} \mathrm{dm}^{-3}\right)$ & 15,2 & 15,1 & 15,0 & 14,1 & 13,1 \\
\hline $\mathrm{Mg}\left(\mathrm{cmol}_{\mathrm{c}} \mathrm{dm}^{-3}\right)$ & 6,3 & 14,7 & 14,6 & 13,8 & 13,0 \\
\hline Zn $\left(\mathrm{mg} \mathrm{dm}^{-3}\right)$ & 5,2 & 40,0 & 40,0 & 40,0 & 40,0 \\
\hline $\mathrm{Cu}\left(\mathrm{mg} \mathrm{dm}^{-3}\right)$ & 1,6 & 1,0 & 1,0 & 1,0 & 1,0 \\
\hline $\mathrm{Fe}\left(\mathrm{mg} \mathrm{dm}^{-3}\right)$ & 341,0 & 163,0 & 168,0 & 161,0 & 130,0 \\
\hline $\mathrm{Mn}\left(\mathrm{mg} \mathrm{dm}^{-3}\right)$ & 42,0 & 191,0 & 175,0 & 183,0 & 198,0 \\
\hline CTC $\left(\mathrm{cmol}_{\mathrm{c}} \mathrm{dm}^{-3}\right)$ & 27,8 & 34,8 & 34,7 & 32,9 & 31,1 \\
\hline $\mathrm{CE}\left(\mu \mathrm{S} \mathrm{cm}^{-1}\right)$ & 1051,8 & 1551,2 & 1321,0 & 1169,3 & 1193,5 \\
\hline CRA (\%) & 119,5 & 134,5 & 165,2 & 186,2 & 204,2 \\
\hline
\end{tabular}

CTC - capacidade de troca catiônica, CE - condutividade elétrica, CRA - capacidade de retenção de água; $\mathrm{T}_{0}$ (Plantmax HA), $\mathrm{T}_{1}$ ( $100 \%$ composto), $\mathrm{T}_{2}(95 \%$ composto $+2,5 \%$ areia $+2,5 \%$ pó de basalto), $\mathrm{T}_{3}\left(90 \%\right.$ composto $+3 \%$ areia $+7 \%$ pó de basalto), $\mathrm{T}_{4}$ ( $85 \%$ composto $+6 \%$ areia $+9 \%$ pó de basalto)

O composto e o pó de basalto foram passados previamente em peneira de malha 6 mesh e a areia em peneira de malha 8 mesh; posteriormente, os componentes foram misturados às combinações e homogeneizados manualmente; o pó de basalto foi acrescentado às misturas com o objetivo de se adicionar nutrientes de liberação lenta aos substratos.

Após a distribuição do substrato nas bandejas, constituindo os respectivos tratamentos, realizou-se a semeadura manual das sementes de almeirão, uma por célula da bandeja. Para evitar o excesso de água nas bandejas após cada irrigação que foi realizada duas vezes ao dia, as mesmas foram mantidas suspensas a uma altura de $0,20 \mathrm{~m}$ do solo, o que facilitou o escoamento do excesso de água; aos 13 e 26 dias após a emergência (DAE) foram avaliados os parâmetros de crescimento visando reduzir o tempo de bandeja das mudas, sendo utilizadas dezesseis plantas por bandeja coletadas aleatoriamente, desprezando-se as bordaduras. 
Avaliaram-se as seguintes características: comprimento de raiz $(\mathrm{CR})$ e comprimento da parte aérea (CPA) obtidos com régua graduada, medindo-se do colo da planta até a extremidade da folha e do colo da planta até a extremidade inferior da raiz, respectivamente; número de folhas por planta $(\mathrm{NF})$ determinado pela contagem direta, partindo-se da folha basal até a última folha totalmente distendida; massa da matéria seca de raiz (MSR) e a massa da matéria seca da parte aérea (MSPA) determinadas após a secagem em estufa com ventilação de ar forçado, por 48 $\mathrm{h}$ a $55^{\circ} \mathrm{C}$, e pesadas em balança eletrônica de precisão; diâmetro do coleto (DC) determinado utilizando-se paquímetro digital.

Para cada substrato foram determinadas a capacidade de retenção de água (CRA) e a porcentagem de carbono, segundo a metodologia proposta por Kiehl (1985) no período anterior à semeadura. O segundo ensaio foi realizado a campo, sendo constituído de quatro blocos casualizados e cinco tratamentos, no total de 20 parcelas, para o que foram levantados canteiros com 0,20 m de altura e 1,20m de largura; os tratamentos foram formados pelas plantas cultivadas nos substratos utilizados em bandejas e a parcela experimental foi constituída de $1,20 \mathrm{x}$ $1,00 \mathrm{~m}$ com área de $1,2 \mathrm{~m}^{2}$, apresentando três linhas longitudinais de plantio com espaçamento $0,30 \times 0,20 \mathrm{~m}$. Uma muda de almeirão foi plantada por cova, totalizando 15 plantas por parcela de cada tratamento.

Prepararam-se os canteiros com enxada rotativa leve (modelo RL 125), pertencente ao Núcleo Experimental de Engenharia Agrícola (NEEA) da Universidade Estadual do este do Paraná (UNIOESTE), antecedendo ao plantio das mudas no local definitivo, sendo cobertos com palhas para manutenção da umidade e redução da temperatura do solo. A adubação dos canteiros foi única para todas as parcelas e realizada com distribuição manual na superfície de $1,0 \mathrm{~kg}$ da mistura de composto, cinza e pó de basalto por metro quadrado. $\mathrm{O}$ composto destorroado foi passado em peneira de malha 6 para melhor homogeneização. No momento em que as mudas atingiram o ponto de transplante, aos 27 dias após a emergência (DAE), elas foram transferidas para os canteiros localizados no NEEA, pertencente à UNIOESTE na BR 467, Km 16, no município de Cascavel, PR. Ressalta-se que as mudas utilizadas foram as cultivadas no primeiro experimento, descrito acima. As plantas foram irrigadas por gotejamento, diariamente, duas vezes ao dia, mantendo-se a umidade do solo próximo à capacidade de campo.

O controle de plantas daninhas foi feito por meio do corte da parte aérea e o controle fitossanitário foi realizado com pulverização de calda bordalesa.

Para as avaliações foi considerada a linha central da parcela desprezando-se as bordaduras. As plantas foram colhidas aos 74 dias após o transplante, removendo-se as folhas inferiores danificadas pelo contato com o solo ou danificadas por insetos, ou seja, folhas com danos potenciais; a seguir, foram lavadas e separadas em raiz e parte aérea e, logo após, secadas ao ambiente. Foram determinados a massa da matéria fresca de raiz (MFR), a massa da matéria fresca da parte aérea (MFPA), o número de folhas (NF) e a área foliar (AF).

A área foliar foi obtida pela Eq. (1).

$$
S=\frac{\pi}{4 C L}
$$

em que:

$$
\begin{array}{ll}
\mathrm{S} & \text { - área foliar, } \mathrm{cm}^{2} \\
\mathrm{C} & \text { - comprimento, } \mathrm{cm} \\
\mathrm{L} & \text { - largura, } \mathrm{cm}
\end{array}
$$

As plantas foram secas em estufa com circulação de ar forçada a $55^{\circ} \mathrm{C}$, até massa constante; após a secagem determinaram-se a MSPA e MSR das plantas.

A pós-colheita foi avaliada utilizando-se amostras de duas plantas de almeirão por parcela, colocadas em estufa BOD a $5^{\circ} \mathrm{C}$ durante sete dias, avaliando-se a perda de massa da matéria fresca; enfim, a porcentagem de perda de massa da matéria fresca foi obtida pela Eq. (2).

$$
\frac{(\mathrm{P} 1-\mathrm{P} 2)}{\mathrm{P} 1} \times 100
$$

em que:

$$
\begin{aligned}
& \mathrm{P}_{1} \text { - a massa inicial, } \mathrm{g} \\
& \mathrm{P}_{2} \text { - a massa após o armazenamento de um dia, } \mathrm{g}
\end{aligned}
$$

No terceiro ensaio utilizou-se o delineamento experimental em blocos casualizados, em parcela subdividida com quatro repetições em que cada unidade experimental foi constituída de uma planta por recipiente, totalizando oito plantas avaliadas por tratamento; as parcelas foram constituídas pelos sete dias de armazenamento em BOD a $5^{\circ} \mathrm{C}$ e as subparcelas pelos mesmos cinco substratos utilizados nas bandejas.

As análises estatísticas foram realizadas utilizando-se o Software Sisvar para Windows, versão 4.3 (Ferreira, 2000) sendo as médias comparadas pelo teste LSD a $5 \%$ de probabilidade.

\section{RESULTADOS E DISCUSSÃO}

Houve diferença significativa nas características CPA, CR, DC, NF, MSPA nas plântulas cultivadas nos diferentes substratos (Tabela 2). Não se observou diferença significativa na MSR aos 13 DAE, demonstrando que as condições para crescimento e a composição dos substratos foram satisfatórias para as plantas, sem ocorrência de efeitos distintos entre os tratamentos.

$\mathrm{Na}$ avaliação do CPA o tratamento $\mathrm{T}_{1}$ superou os demais aos 13 DAE, alcançando altura de plantas de $4,50 \mathrm{~cm}$, que pode estar relacionado aos teores de fósforo do composto que favorece o crescimento inicial vigoroso e a retenção de água pelo substrato. Os substratos $\mathrm{T}_{2}(4,08 \mathrm{~cm}), \mathrm{T}_{3}(4,24 \mathrm{~cm})$ e $\mathrm{T}_{4}$ $(4,32 \mathrm{~cm})$ mesmo propiciando maior $\mathrm{CPA}$ em relação ao $\mathrm{T}_{0}(3,48$ $\mathrm{cm})$, não alcançaram alturas próximas ao mínimo $(6 \mathrm{~cm})$ necessário para transplante devido, possivelmente, ao espaço reduzido das células da bandeja. Segundo Resende et al. (2003), o maior desenvolvimento das mudas se deve à quantidade e à disponibilidade de nutrientes nas bandejas de 128 células, o que justifica a antecipação no transplante da alface. 
Tabela 2. Valores médios dos parâmetros avaliados nas plântulas de almeirão, aos 13 e 26 dias após a emergência (DAE)

\begin{tabular}{|c|c|c|c|c|c|c|}
\hline \multirow{2}{*}{ Trat } & CPA & CR & \multirow{2}{*}{$\begin{array}{c}D C \\
(\mathrm{~mm})\end{array}$} & \multirow{2}{*}{ NF } & MSPA & MSR \\
\hline & \multicolumn{2}{|c|}{ (cm) } & & & \multicolumn{2}{|c|}{ (mg) } \\
\hline $\begin{array}{l}\mathrm{T}_{0} \\
\mathrm{~T}_{1} \\
\mathrm{~T}_{2} \\
\mathrm{~T}_{3} \\
\mathrm{~T}_{4}\end{array}$ & $\begin{array}{l}3,48 c \\
4,50 a \\
4,08 \mathrm{~b} \\
4,24 \mathrm{ab} \\
4,32 \mathrm{ab}\end{array}$ & $\begin{array}{l}7,27 a \\
6,07 b c \\
6,70 a b \\
6,21 b c \\
5,79 c\end{array}$ & $\begin{array}{l}13 \mathrm{DAE} \\
0,86 \mathrm{ab} \\
0,91 \mathrm{a} \\
0,92 \mathrm{a} \\
0,84 \mathrm{~b} \\
0,84 \mathrm{~b}\end{array}$ & $\begin{array}{l}4,08 \mathrm{~b} \\
4,08 \mathrm{~b} \\
4,00 \mathrm{~b} \\
4,00 \mathrm{~b} \\
4,42 \mathrm{a}\end{array}$ & $\begin{array}{r}9,40 \mathrm{~b} \\
13,37 \mathrm{a} \\
12,82 \mathrm{a} \\
13,45 \mathrm{a} \\
13,87 \mathrm{a} \\
\end{array}$ & $\begin{array}{l}2,88 a \\
3,02 a \\
2,78 a \\
3,45 a \\
2,78 a\end{array}$ \\
\hline $\begin{array}{l}\text { DMS } \\
\text { CV }(\%)\end{array}$ & $\begin{array}{r}0,49 \\
14,09\end{array}$ & $\begin{array}{r}0,78 \\
14,87\end{array}$ & $\begin{array}{l}0,06 \\
8,99\end{array}$ & $\begin{array}{l}0,24 \\
7,14\end{array}$ & $\begin{array}{r}2,05 \\
19,89 \\
\end{array}$ & $\begin{array}{r}1,65 \\
67,60\end{array}$ \\
\hline $\begin{array}{l}\mathrm{T}_{0} \\
\mathrm{~T}_{1} \\
\mathrm{~T}_{2} \\
\mathrm{~T}_{3} \\
\mathrm{~T}_{4}\end{array}$ & $\begin{array}{l}4,97 \mathrm{c} \\
9,49 \mathrm{a} \\
9,60 \mathrm{a} \\
9,40 \mathrm{a} \\
8,44 \mathrm{~b}\end{array}$ & $\begin{array}{l}9,90 \mathrm{a} \\
8,73 \mathrm{~b} \\
8,53 \mathrm{~b} \\
7,98 \mathrm{~b} \\
8,51 \mathrm{~b}\end{array}$ & $\begin{array}{l}26 \mathrm{DAE} \\
1,32 \mathrm{c} \\
1,66 \mathrm{~b} \\
1,64 \mathrm{~b} \\
1,92 \mathrm{a} \\
1,84 \mathrm{ab}\end{array}$ & $\begin{array}{l}3,00 \mathrm{~b} \\
3,83 \mathrm{a} \\
4,08 \mathrm{a} \\
4,00 \mathrm{a} \\
3,92 \mathrm{a}\end{array}$ & $\begin{array}{l}27,89 \mathrm{c} \\
65,39 \mathrm{~b} \\
81,57 \mathrm{ab} \\
98,87 \mathrm{a} \\
75,55 \mathrm{~b}\end{array}$ & $\begin{array}{l}23,42 \mathrm{~b} \\
23,80 \mathrm{~b} \\
32,85 \mathrm{a} \\
32,32 \mathrm{ab} \\
36,25 \mathrm{a}\end{array}$ \\
\hline $\begin{array}{l}\text { DMS } \\
\text { CV (\%) }\end{array}$ & $\begin{array}{r}0,89 \\
13,04 \\
\end{array}$ & $\begin{array}{r}1,12 \\
15,74\end{array}$ & $\begin{array}{r}0,21 \\
15,09 \\
\end{array}$ & $\begin{array}{r}0,34 \\
11,03 \\
\end{array}$ & $\begin{array}{l}18,84 \\
32,96\end{array}$ & $\begin{array}{r}8,97 \\
36,89 \\
\end{array}$ \\
\hline
\end{tabular}

CPA - comprimento da parte aérea, CR - comprimento da raiz, DC - diâmetro do coleto, NF - número de folhas, MSR - massa da matéria seca de raiz, MSPA - massa da matéria seca da parte aérea; DMS - diferença mínima significativa; Médias seguidas de mesma letra na coluna não diferem entre si pelo teste LSD a $5 \%$ de probabilidade; T(Plantmax HA), $T_{1}(100 \%$ composto) $\mathrm{T}_{2}\left(95 \%\right.$ composto $+2,5 \%$ areia $+2,5 \%$ pó de basalto), $\mathrm{T}_{3}(90 \%$ composto $+3 \%$ areia $+7 \%$ pó de basalto), $T_{4}(85 \%$ composto $+6 \%$ areia $+9 \%$ pó de basalto)

Aos 26 DAE o CPA apresentou incremento de aproximadamente $100 \%$ para os tratamentos $\mathrm{T}_{1}(9,49 \mathrm{~cm}), \mathrm{T}_{2}(9,60 \mathrm{~cm})$ e $\mathrm{T}_{3}$ $(9,44 \mathrm{~cm})$ em relação aos valores observados aos $13 \mathrm{DAE}$, porém para o tratamento $\mathrm{T}_{0}$ este incremento foi de apenas $42 \%$, fato que aponta maior quantidade de nutrientes presentes no composto orgânico haja vista que esses são disponibilizados às mudas de forma gradual. A medida em que ocorreram reduções nas porcentagens de composto nos substratos, houve alteração no CPA. Souza et al. (2008) relatam, utilizando seis misturas de solo e coprólitos de minhoca $(0,20,40$ 60, 80 e $100 \%)$ como substratos para produção de mudas de alface, que a condição de fertilidade do substrato foi lentamente diminuída, conforme o solo foi substituído por níveis crescentes de coprólitos de minhoca.

Analisando a característica $\mathrm{CR}$, o substrato $\mathrm{T}_{0}$ alcançou maiores valores nas duas avaliações, 13 e 26 DAE, medindo 7,27 e 9,90 cm porém foi semelhante ao $T_{2}$ na primeira avaliação. $\mathrm{O}$ resultado obtido em $\mathrm{T}_{0}$ pode estar relacionado à densidade do substrato que apresenta baixa resistência e maior espaço poroso. É provável que o aumento do $\mathrm{CR}$ no $\mathrm{T}_{2}$ tenha sido influenciado pela aeração devido à adição de areia ao substrato. Trani et al. (2007) ressaltam que a aeração é fundamental para respiração das células das raízes e para o desenvolvimento adequado das plantas. No caso do $\mathrm{T}_{0}$ houve baixa densidade $\mathrm{e}$ menor espaço de ar na capacidade de campo obtendo-se CR de 10,30 cm (Smiderle et al., 2001).

O CR obtido aos 13 DAE com o $\mathrm{T}_{0}$ correspondeu ao da segunda avaliação aos $26 \mathrm{DAE}$, proporcionando maior crescimento do sistema radicular, o que se deve, possivelmente, ao crescimento das raízes finas.

Os substratos $\mathrm{T}_{1}$ e $\mathrm{T}_{2}$ foram superiores aos demais para a característica DC aos 13 DAE com 0,91 e 0,92 mm, respectivamente, e não diferiram de $\mathrm{T}_{0}$; na segunda avaliação, aos 26 DAE, os melhores resultados foram obtidos pelo $\mathrm{T}_{3} \mathrm{e}$ $\mathrm{T}_{4}$, fato que pode ser atribuído à maior capacidade de retenção de água desses substratos, que propiciaram acúmulo de massa seca pelas plantas e maior lignificação dos tecidos do coleto.

Para o NF, o $\mathrm{T}_{4}$ foi estatisticamente superior aos demais tratamentos aos $13 \mathrm{DAE}$, enquanto aos 26 DAE o substrato que apresentou o menor $\mathrm{NF}$ foi o $\mathrm{T}_{0}$; isto pode estar relacionado ao tipo de substratos utilizados nas bandejas, sobretudo pela presença do composto que, provavelmente, supriu as plantas quando comparadas ao $\mathrm{T}_{0}$. Segundo Trani et al. (2004), a partir dos 10 dias após a emergência o tipo de substratos começou a promover efeito nas mudas de alface quanto ao número de folhas. Duarte et al. (2006) obtiveram 4,15 folhas em substrato constituído de vermicomposto bovino mais casca de arroz carbonizada, valor este superior aos encontrados neste trabalho, tanto aos 13 como aos $26 \mathrm{DAE}$.

Aos 13 DAE a MSPA foi similar entre os tratamentos com composto, sendo que o $\mathrm{T}_{0}$ apresentou o menor acúmulo 9,40 $\mathrm{mg}$, resultado que pode estar relacionado à baixa capacidade do substrato $\mathrm{T}_{0}$ - HA em disponibilizar nutrientes, o que promoveu efeitos depressivos na parte aérea do almeirão. Castro et al. (2003) verificaram que os substratos industriais (Plantmax contendo vermiculita e Plantmax sem vermiculita), demonstraram ser inferiores aos orgânicos no desenvolvimento de mudas de beterraba, medida por meio da área foliar e MSPA. Possivelmente isto tenha ocorrido pelos maiores conteúdos de nutrientes, exceto $\mathrm{Ca}$ e $\mathrm{Mg}$, em relação aos substratos industriais.

O substrato que favoreceu o maior acúmulo de MSPA aos $26 \mathrm{DAE}$ foi $\mathrm{T}_{3}$ que não diferiu de $\mathrm{T}_{2}$, ambos superiores ao $\mathrm{T}_{0}$. Observa-se que o acúmulo de MSPA se manteve superior na presença de composto orgânico e pó de basalto, por ocasião do transplante, mas as misturas contribuíram para a não ocorrência de diferença entre $\mathrm{T}_{2}$ e $\mathrm{T}_{3}$, mesmo com composições distintas entre os substratos. Araújo Neto et al. (2009) relatam que a não diferença significativa entre os substratos alternativos (composto orgânico, esterco bovino e casca de arroz carbonizada com presença ou ausência de coprólito de minhoca) para as características número de folhas e MSPA em pimentão foi devida à contribuição de um dos fatores à constituição com casca de arroz carbonizada, o que possibilitou maior porosidade, aeração e capacidade de retenção de água.

Observa-se, para a MSR, que na primeira avaliação não apresentou diferença significativa entre os tratamentos (Tabela 2), porém aos $26 \mathrm{DAE}$ os substratos $\mathrm{T}_{2}, \mathrm{~T}_{3}$ e $\mathrm{T}_{4}$ apresentaram os melhores desempenhos enquanto o menor desenvolvimento em termos absolutos coube ao $\mathrm{T}_{0}$. A pouca quantidade de raiz em $\mathrm{T}_{0}$ no momento da avaliação na bandeja por ocasião do transplante, evidenciou dificuldade para retirada das mudas das células devido à não formação de torrão, o que também foi observado por Modolo et al. (2001). É preciso considerar, ainda, que a raiz do almeirão é pivotante, sem ramificações laterais, característica que dificulta o transplante (Filgueira, 2000) e se torna mais evidenciada em substratos que servem apenas para fixação do sistema radicular. Além da formação adequada de torrão nos substratos à base de composto, observaram-se plantas com maior MSR nos substratos que continham misturas na sua constituição, com $\mathrm{T}_{2}$ e $\mathrm{T}_{4}$ sendo semelhantes ao $\mathrm{T}_{3} \mathrm{e}$ 
demonstrando superioridade aos $\mathrm{T}_{0}$ e $\mathrm{T}_{1}$. $\mathrm{O}$ aumento da MSR se relaciona, sem dúvida, com os acréscimos de pó de basalto, contribuindo para liberação lenta e prolongada de nutrientes e areia, propiciando porosidade aos substratos.

$\mathrm{Na}$ avaliação das plantas de almeirão após o transplante, houve diferenças significativas apenas na MSPA, NF e MFPA, em relação aos substratos empregados (Tabela 3 ) indicando que as raízes do almeirão obtiveram condições iguais para o seu desenvolvimento, como: nutrientes, água e espaço físico, proporcionados pela adubação orgânica, pelo preparo do canteiro e pela manutenção da palha na superfície do solo. Segundo Roel et al. (2007) a adubação orgânica adicionada ao solo propicia efeito imediato e residual, pela sua decomposição lenta e liberação gradual de nutrientes.

Andrade Júnior et al. (2005) verificaram que a cobertura do canteiro com casca de café promoveu crescimento e desenvolvimento adequados da alface; além disto, a variação no desenvolvimento radicular das mudas observada em bandeja promoveu resultados semelhantes em canteiro, superando as diferenças avaliadas devido, possivelmente, à cobertura morta existente e à facilidade de penetração das raízes, pois o solo dos canteiros foi revolvido antes do transplante.

O NF foi superior em todos os substratos que continham composto em relação ao $\mathrm{T}_{0}$, sendo semelhantes aos resultados obtidos em bandeja aos 26 DAE. Sugere-se que isto esteja relacionado ao fornecimento gradual e equilibrado de nutrientes do composto durante a formação das mudas e ao número de linhas utilizado em canteiro, que possibilitou espaço para aumento da quantidade de folhas das plantas com melhor desenvolvimento. Zárate et al. (2006) verificaram, trabalhando com produção de almeirão em cultivo solteiro e consorciado com cenoura, maior NF das plantas no cultivo solteiro, 350 folhas por metro quadrado aos 164 dias, em cultivo com quatro linhas de plantas de almeirão por canteiro.

O comportamento adequado das mudas em bandeja nem sempre corresponde ao seu melhor desempenho em canteiro, pois a MSPA variou dentre os substratos desde os $13 \mathrm{DAE}$, até a colheita. Neste caso, os tratamentos à base de composto tiveram melhor desempenho em comparação ao $\mathrm{T}_{0}$. As plantas desenvolvidas em $T_{2}$ apresentaram maior MFPA correspondendo aos acúmulos de MSPA superando $\mathrm{T}_{0}$ e $\mathrm{T}_{4}$. Esses resultados estão relacionados, sem dúvida, ao desenvolvimento adequado das mudas em bandeja, o que permitiu o estabelecimento satisfatório em canteiro, resultando em plantas com maiores massas secas, pela manutenção da palha de aveia na superfície do solo. Mogor e Câmara (2007) verificaram influência das coberturas do solo no desenvolvimento inicial da alface, comparando a massa da matéria fresca das plantas, que foi menor no solo sem cobertura vegetal em três cultivares de alface: lisa, crespa e americana. As cultivares de alface (lisa, crespa, americana) sem cobertura de aveia apresentaram, aos 12 dias 24,47, 18,70 e 18,40 g planta $^{-1}$ respectivamente, enquanto as plantas submetidas à cobertura com aveia ceifada apresentaram 34,60, 29,45 e 30,72 g planta $^{-1}$ respectivamente.

$\mathrm{Na}$ avaliação da pós-colheita houve diferença significativa entre os substratos. De acordo com a Figura 1 e conforme os dias passam, ocorrem perdas de massa das plantas de almeirão pois houve variações entre os tratamentos.

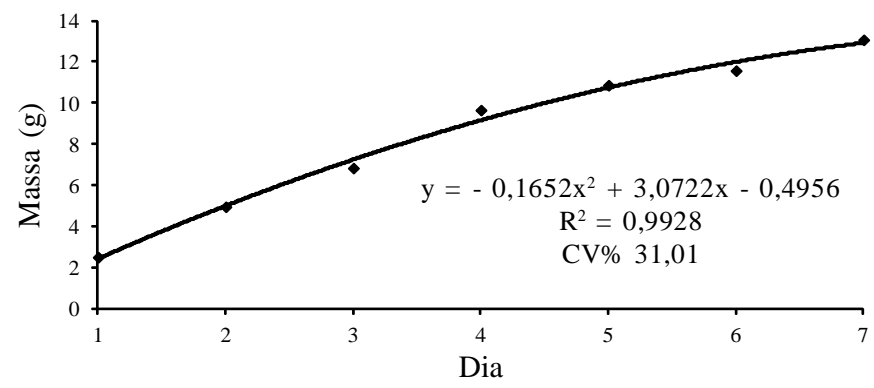

Figura 1. Perdas de massa das plantas de al meirão durante o perío do de armazenamento

Ocorreu perda de massa da matéria fresca pelas plantas com o aumento do período de armazenamento, alcançando valores máximos aos 7 dias (Figura 1). As maiores diferenças entre os tratamentos foram verificados nos primeiros 4 dias, sendo os dias mais críticos para perda de água pelas folhas, indicando que a respiração das folhas foi maior neste período, havendo redução da respiração com valores semelhantes estatisticamente aos 6 e 7 dias. A perda acelerada de água possivelmente seja pelo resfriamento rápido do almeirão fazendo com que os estômatos ficassem abertos (Chitarra \& Chitarra, 2005).

Apresenta-se na, Tabela 4, a perda de massa do almeirão por tratamento, devido à armazenagem.

Constatou-se perda máxima de água do almeirão nos quatro dias após o armazenamento no $\mathrm{T}_{1}$ com redução da respiração a

Tabela 3. Valores médios dos parâmetros avaliados nas plantas de al meirão aos 74 dias após o transplante. U N IO ESTE, Cascavel, PR, 2009

\begin{tabular}{|c|c|c|c|c|c|c|c|c|}
\hline \multirow{2}{*}{ Tratamento } & \multirow{2}{*}{$\begin{array}{c}\text { AF } \\
\left(\mathrm{cm}^{2}\right)\end{array}$} & CR & CPA & \multirow{2}{*}{ NF } & MFR & MFPA & MSR & MSPA \\
\hline & & \multicolumn{2}{|c|}{$(\mathrm{cm})$} & & \multicolumn{4}{|c|}{ (g) } \\
\hline $\mathrm{T}_{0}$ & $381,10 \mathrm{c}$ & $22,02 \mathrm{a}$ & $29,26 a$ & $11,83 \mathrm{~b}$ & 7,42 a & $149,97 \mathrm{c}$ & $1,30 \mathrm{a}$ & $8,59 \mathrm{c}$ \\
\hline $\mathrm{T}_{1}$ & $486,68 \mathrm{~b}$ & $20,87 a$ & $31,77 a$ & $16,92 \mathrm{a}$ & $9,17 \mathrm{a}$ & $277,02 a b$ & $1,72 \mathrm{a}$ & $14,81 a b$ \\
\hline $\mathrm{T}_{2}$ & $557,94 \mathrm{a}$ & $22,88 a$ & $35,57 \mathrm{a}$ & $16,58 \mathrm{a}$ & $10,98 \mathrm{a}$ & $324,34 \mathrm{a}$ & $1,97 \mathrm{a}$ & 18,22 a \\
\hline $\mathrm{T}_{3}$ & $473,34 b$ & 21,82 a & $32,38 a$ & $17,33 \mathrm{a}$ & $10,64 a$ & $273,07 a b$ & $1,97 \mathrm{a}$ & $16,07 \mathrm{ab}$ \\
\hline $\mathrm{T}_{4}$ & $475,21 \mathrm{~b}$ & $20,43 \mathrm{a}$ & 31,63 a & $16,33 \mathrm{a}$ & $8,72 \mathrm{a}$ & $237,87 \mathrm{~b}$ & $1,51 \mathrm{a}$ & $13,24 b c$ \\
\hline DMS & 61,97 & 2,62 & 4,13 & 3,48 & 3,59 & 69,67 & 0,69 & 4,96 \\
\hline CV (\%) & 28,05 & 14,83 & 15,71 & 26,89 & 46,66 & 33,69 & 49,98 & 42,69 \\
\hline
\end{tabular}

Médias seguidas de mesma letra na coluna não diferem entre si pelo teste $L S D$ a $5 \%$ de probabilidade; $T_{0}$ (Plantmax HA), $T_{1}$ ( $100 \%$ composto), $T_{2}(95 \%$ composto $+2,5 \%$ areia $+2,5 \%$ pó de basalto) $\mathrm{T}_{3}\left(90 \%\right.$ composto $+3 \%$ areia $+7 \%$ pó de basalto), $\mathrm{T}_{4}(85 \%$ composto $+6 \%$ areia $+9 \%$ pó de basalto); $\mathrm{AF}$ - área foliar, CR - comprimento de raiz, CPA - comprimento de parte aérea, NF - número de folhas, MFR - massa da matéria fresca de raiz, MFPA - massa da matéria fresca de parte aérea, MSR - massa da matéria seca de raiz, MSPA - massa da matéria seca de parte aérea; DMS - diferença mínima significativa 
Tabela 4. Perda de massa do almeirão nos diferentes substratos devido ao armazenamento de 7 dias em póscolheita

\begin{tabular}{cc}
\hline Tratamento & Perda de massa (g) \\
$\mathrm{T}_{0}$ & $7,66 \mathrm{~b}$ \\
$\mathrm{~T}_{1}$ & $10,29 \mathrm{a}$ \\
$\mathrm{T}_{2}$ & $7,91 \mathrm{~b}$ \\
$\mathrm{~T}_{3}$ & $8,65 \mathrm{~b}$ \\
$\mathrm{~T}_{4}$ & $7,94 \mathrm{~b}$ \\
\hline $\mathrm{DMS}$ & 1,19 \\
$\mathrm{CV}(\%)$ & 26,42 \\
\hline
\end{tabular}

Médias seguidas de mesma letracna coluna não diferem entre si pelo teste LSD a 0,05 de probabilidade; $\mathrm{T}_{\text {( }}$ (Plantmax HA), $\mathrm{T}_{1}$ ( $100 \%$ composto), $\mathrm{T}_{2}$ ( $95 \%$ composto $+2,5 \%+$ areia $+2,5 \%$ pó de basalto), $\mathrm{T}_{3}$ ( $90 \%$ compos to $+3 \%$ areia $+7 \%$ pó de basalto), $\mathrm{T}_{4}$ ( $85 \%$ composto $+6 \%$ areia + $9 \%$ pó de basalto); DMS - diferença mínima significativa

partir do $5^{\circ}$ dia, minimizando a perda de massa da matéria fresca. A elevada perda de massa da matéria fresca pelas plantas em $\mathrm{T}_{1}$ até o quarto dia de armazenamento, possivelmente seja devida ao tamanho das plantas e à AF com maior conteúdo de água. Apesar das elevadas doses de composto propiciarem maior conteúdo de água nas plantas, Santos et al. (2001) encontraram redução progressiva da perda de massa da matéria fresca em alface quando aumentada a dose de composto utilizada (de 22,8 a 91,2 $\mathrm{t} \mathrm{ha}^{-1}$ ). Com isto, as perdas de massa da matéria fresca foram menores nos tratamentos com mistura de composto, pó de basalto e areia e, inclusive, no tratamento $\mathrm{T}_{0}$, que apresentou plantas menores em comparação ao tratamento com composto $\left(\mathrm{T}_{1}\right)$ Os resultados obtidos em $\mathrm{T}_{0}$ foram semelhantes aos dos demais tratamentos mas isto é devido, provavelmente, ao menor NF e, consequentemente, à menor AF apresentada no momento da colheita.

\section{CONClusões}

1. Os substratos orgânicos $T_{2}$ e $T_{3}$ são recomendados para produção de mudas de almeirão com desenvolvimento satisfatório em sistema de cultivo em bandejas e a campo e, de igual forma, em pós-colheita.

2. O uso de composto orgânico como substrato propicia o desenvolvimento de mudas mais vigorosas e plantas mais resistentes no campo quando comparado com o substrato comercial.

\section{LITERATURA CITADA}

Andrade Júnior,V. C.; Yuri, J. E.; Nunes, U. R.; Pimenta, F. L.; Matos, C. S. M.; Florio, F. C. A.; Madeira, D. M. Emprego de tipos de cobertura de canteiro no cultivo da alface. Horticultura Brasileira, v.23, p.899-903, 2005.

Araujo Neto, S. E.; Azevedo, J. M. A.; Galvão, R. O.; Oliveira, E. B. L.; Ferreira, R. L. F. Produção de muda orgânica de pimentão com diferentes substratos. Ciência Rural, v.39, p.1408-1413, 2009.

Blanck A F; Blanck M. F. A; Silva, P.A; Torres, M. E. R.; MENEZES, H. J. A. Efeitos de composições de substratos na produção de mudas de quiôiô (Ocimum gratissimum L.). Revista Ciência Agronômica, v.34, p.5-8, 2003.
Castro, C. M.; Ribeiro, R. L. D.; Almeida, D. L. Caracterização e avaliação de substratos orgânicos para produção de mudas de beterraba. Agronomia, v.37, p.19-24, 2003.

Chitarra, M. I. F.; Chitarra, A. B. Pós-colheita de frutas e hortaliças: fisiologia e manuseio. 2. ed., Lavras: UFLA, 2005. $785 \mathrm{p}$.

Duarte, T. S.; Paglia, A. G.; Fernandes, H. S. Formulação de substratos orgânicos para produção de mudas de tomateiro. Revista Brasileira de Agroecologia, v.1, p.1-4, 2006.

Echer, M. M.; Guimarães, V. F.; Aranda, A. N.; Bortolazzo, E. D.; Braga, J. S. Avaliação de mudas de beterraba em função do substrato e do tipo de bandeja. Semina: Ciências Agrárias, v.28, p.45-50, 2007.

Factor, T. L.; Araújo, J. A. C.; Vilella Júnior, L. V. E. Produção de pimentão em substratos e fertirrigação com efluente de biodigestor. Revista Brasileira de Engenharia Agrícola e Ambiental ,Campina Grande, v.12, p.143-149, 2008.

Fernandes, C.; Corá, J. E.; Braz, L. T. Desempenho de substratos no cultivo do tomateiro do grupo cereja. Horticultura Brasileira, v.24, p.42-46, 2006.

Ferreira, D. F. Manual do sistema Sisvar para análises estatísticas. Lavras: UFLA, 2000, 66p.

Filgueira, F. A. R. Novo manual de olericultura: agrotecnologia moderna na produção e comercialização de hortaliças. Viçosa: UFV, 2000. 402p.

Heredia Zárate, N.A.; Vieira, M. C.; Graciano, J. D.; Pezzoni Filho, J. C. Produção de almeirão em cultivo solteiro e consorciado com cenoura. Acta Scientiarum. Agronomy, v.28, p.55-61, 2006.

IAPAR - Instituto Agronômico do Paraná. Cartas climáticas do Estado do Paraná. Londrina: IAPAR, 1994, 49p.

Kiehl, E. J. Fertilizantes Orgânicos. Piracicaba: Agronômica Ceres Ltda., 1985. 492p.

Leal, M. A. A.; Guerra, J. G. M.; Peixoto, R. T. G.; Almeida, D. L. Utilização de compostos orgânicos como substratos na produção de mudas de hortaliças. Horticultura Brasileira, v.25, p.392-395, 2007.

Modolo, V. A.; Tessarioli Neto, J.; Ortigozza, L. E. R. Produção de frutos de quiabeiro a partir de mudas produzidas em diferentes tipos de bandejas e substratos. Horticultura Brasileira, v.19, p.39-42, 2001.

Mogór, A. F. Câmara, F. L. A. Produção de alface no sistema orgânico em sucessão a aveia preta, sobre a palha, e diferentes coberturas do solo. Scientia Agraria, v.8, p.239245, 2007.

Oliveira, D. A.; Fernandes, M. B.; Rodrigues, J. J. V.; Oliveira, R. A.; Costa, F. G. B. Produção de mudas de pimentão e alface em diferentes combinações de substrato. Revista Verde, v.3, p.133-137, 2008.

Reghin, M. Y.; Otto, R. F.; Jacoby,C. F. S.; Olinik, J. R. Efeitos do tipo de bandejas e de cultivares na produção de plântulas e no rendimento da chicória. Ciência e Agrotecnologia, v.30, p.435-443, 2006. 
Resende, G. M.; Yuri, J. E.; Mota, J. H.; Souza, R. J.; Freitas, S. A. C.; Rodrigues Júnior, J. C. Efeitos de tipos de bandejas e idade de transplantio de mudas sobre o desenvolvimento e produtividade de alface americana. Horticultura Brasileira, v.21, p.558-563, 2003.

Roel, A. R.; Leoanel, LA K; Favaro, S.P.; Zatarim, M.; Momesso, C. M. V.; Soares, M. V. Avaliação de fertilizantes orgânicos na produção de alface em Campo Grande, MS. Scientia Agraria, v.8, p.325-329, 2007.

Santos, R. H.S.; Silva, F.; Casali, V. W. D.; Condo, A. R. Conservação pós-colheita de alface cultivada com composto orgânico. Pesquisa Agropecuária Brasileira, v.36, p.521-525, 2001.

Sediyama, M. A. N.; Ribeiro, J. M.; Albanez, A. C. In: Paula Junior, T. J.; Venzon, M. (ed.). 101 culturas: Manual de tecnologias agrícolas. Belo Horizonte: EPAMIG, 2007. p. 665-674.

Silveira, E. B.; Rodrigues, V. J. L. B.; Gomes, A. M. A.; Mariano, R. L. R; Mesquitta, J. C. P. Pó de coco como substrato para produção de mudas de tomateiro. Horticultura Brasileira, v.20, p.211-216, 2002.
Smiderle, O. J.; Salibe, A. B.; Hayashi, A. H.; Minami, K. Produção de mudas de alface, pepino e pimentão em substratos combinando areia, solo e Plantmax ${ }^{\circledast}$. Horticultura Brasileira, v.19, p.253-257, 2001.

Souza, S. R.; Fontinele, Y. R.; Saldanha, C. S.; Araújo Neto, S. E.; Kusdra, J. F. Produção de mudas de alface com o uso de substrato preparado com coprólitos de minhoca. Ciência e Agrotecnológia, v.32, p.115-121, 2008.

Trani, P. E.; Feltrin, D. M.; Pott, C. A.; Schwingel, M. Avaliação de substratos para produção de mudas de alface. Horticultura Brasileira, v.25, p.256-260, 2007.

Trani, P. E.; Novo, M. C. S. S.; Cavallaro Júnior, M. L.; Telles, L. M. G. Produção de mudas de alface em bandejas e substratos comerciais. Horticultura Brasileira, v.22, p.290294, 2004.

Wagner Júnior, A.; Silva, J. O. C.; Santos, C. E. M.; Pimentel, L. D.; Negreiros, J. R. S.; Alexandre, R. S.; Bruckner, C. H. Substratos na formação de mudas para pessegueiro. Acta Scientiarum. Agronomy, v.29, p.569-572, 2007. 